\title{
The Influence of Parameters of the Resistance Projection Welding of M10 Steel Nuts to the Galvanized Steel Sheet DP 600 on Selected Joint Characteristics
}

Pavol Sejč, Judita Belanová, Zuzana Gábrišová, Branislav Vanko

Faculty of Mechanical Engineering, Slovak University of Technology in Bratislava, Nám.Slobody17, 81231 Bratislava.Slovak Republic. E-mail: pavol.sejc@stuba.sk, judita.belanova@stuba.sk, zuzana.gabrisova@stuba.sk, branislav.vanko@stuba.sk.

Projection welding belongs to the group of resistance welding technologies. The basic process parameters are the welding current and the current flow time. The resistance projection weldability of the fasteners on metal sheets is not as well understood as the resistance spot weldability of the sheets, so complex studies for the wider application of resistance welding of nuts in the automotive industry are still needed. This research is aimed at valuation the effect of resistance projection welding parameters (steel nuts on galvanized steel sheet DP 600) on joint properties. The hard welding mode (high welding current, clamping force and short welding time) provided 2 times higher strength of the weld joints as the soft welding mode. When using the soft welding mode, an increased $\mathrm{Zn}$ concentration from the sheet metal coating was measured in the transition area between the welded materials at the folding locations. When applying the hard welding mode, only a slight increase in the $\mathrm{Zn}$ concentration was observed at the inner boundary of the weld joint.

Keywords: Resistance projection welding, galvanized steel, hardness and structure of the weld joint.

\section{Introduction}

Car bodies currently contain about 300 welded and clamped fasteners, such as bolts, nuts and pins to which safety elements are fastened including safety belts, steering or grounding posts of electrical circuits [1]. Stud welding processes (no. 78 according to STN EN ISO 4063) [2] or resistance projection welding (no. 23 according to STN EN ISO 4063) [3] are used for their welding $[4,5]$. From the point of view of the safety and reliability of the products, the quality of the welded joints is crucial.

Projection welding belongs to the group of resistance welding processes. The basic process parameters are the welding current and the current flow time that will affect the amount of heat by relation (1) [6]:

$$
Q=R \cdot I^{2} \cdot t
$$

Where:

Q...heat, [J],

R...electrical resistance, $[\Omega]$,

I ...electric current, $[\mathrm{A}]$,

$\mathrm{t}$... current flow time. [s].

Another important process parameter is the clamping force $F(N)$.

Suitable parameters of resistance welding can generally be obtained from the lobe diagram, which is the dependence of the welding time on the electric current for a concrete material combination and joining conditions. The window of operation includes conditions for the hard welding mode (high current and clamping force at short welding time) and soft welding mode (low current and clamping force at long welding time). The basic starting points for determining suitable resistance welding conditions are primarily information about the chemical composition and thickness of joined materials.

The influence of the type of projections, the amount of the welding current and the clamping force on resistance projection welding of the steel nuts with sheets of dual-phase (DP) steels have been described by authors Wang and Zhang [7]. In their work they documented the significant influence of the type of projections on the heat distribution during heating, on the other hand, only a small importance of the clamping force on the weld joint dimension. Other authors have also studied the impact of configuration and dimensions of projections [8-10], respectively the system of applying the clamping force [11] to the resulting properties of the joint. For this purpose, various simulation models have been designed and tested to obtain new knowledge about the process of heating and deformation at welded joints.

In addition to the basic data needed to select resistance welding parameters, there are many other factors that will significantly influence the selection of appropriate process variables. As the results of the published works show, the surface quality of the joined materials will also play an essential role in resistance heating. E.g. Wang in his work [12] pointed out that the type of surface treatment of the galvanized steel sheets will have a major impact on the weldability in 
resistance projection welding.

Although the resistance projection welding of nuts on galvanized steel sheets is widely used in industry, only a few research articles have been published. The weldability of the fasteners on metal sheets is not as well understood as the resistance spot weldability of the sheets, so complex studies for the wider application of resistance welding of nuts in the automotive industry are still needed. This research is aimed at valuation the effect of resistance projection welding parameters (steel nuts on galvanized steel sheet DP 600) on joint properties.

\section{Experimental part}

A two-side galvanized steel sheet DP 600 was used for the production of test specimens. The sheet thickness was $2.60 \mathrm{~mm}$. The average $\mathrm{Zn}$ layer thickness was $13.52 \mu \mathrm{m}$. The chemical composition and selected mechanical properties of the material are shown in Tab.1 and Tab.2.

The M10 steel nuts without surface treatment were welded on galvanized metal sheets with pre-drilled holes by resistance projection welding. The nuts were made of carbon steel, the chemical composition is shown in Tab. 3. The shape and basic dimensions of the nuts and the overall view from the side of the sixsided head and projections are shown in Fig. 1. The split projection on the annular part of the nut consisted of three parts.

Tab.1 Selected mechanical properties of steel sheet DP 600

\begin{tabular}{|c|c|c|c|}
\hline Steel sheet & $\mathrm{R}_{\mathrm{m}}[\mathrm{MPa}]$ & $\mathrm{R}_{\mathrm{p} 0,2}[\mathrm{MPa}]$ & $\mathrm{A}_{80}[\%]$ \\
\hline DP 600 & 600 & 350 & 22 \\
\hline
\end{tabular}

Tab.2 Chemical composition of steel sheet DP 600 (wt. \%)

\begin{tabular}{|c|c|c|c|c|c|c|}
\hline Steel sheet & $\mathrm{C}$ & $\mathrm{Si}$ & $\mathrm{Mn}$ & $\mathrm{P}$ & $\mathrm{S}$ & $\mathrm{Al}$ \\
\hline DP 600 & 0.11 & 0.05 & 1.44 & 0.012 & 0.0005 & 1.250 \\
\hline
\end{tabular}

Tab.3 Chemical composition of nuts (wt. \%)

\begin{tabular}{|c|c|c|c|c|c|c|}
\hline Nut & C & Si & Mn & P & S & N \\
\hline M10 & 0.19 & 0.3 & $0.25 \div 0.50$ & 0.050 & 0.050 & 0.007 \\
\hline
\end{tabular}

For welding, stationary resistance welding machines of type BP 80 or L 250 were used. Both machines allowed to adjust the course of the welding cycle according to Fig. 2. The machine BP 80 used a soft welding mode - a smaller welding current, and a longer welding time with a heat treatment of the welded joint (Tab. 4). On the contrary, the L 250 used a hard welding mode - a higher welding current, and a shorter time without annealing the weld joint (Tab. 5).

Tab.4 Soft welding mode parameters

\begin{tabular}{|c|c|c|c|}
\hline \multirow{2}{*}{$\begin{array}{c}\text { The welding } \\
\text { process } \\
\text { interval }\end{array}$} & \multicolumn{3}{|c|}{ Set values } \\
\cline { 2 - 4 } & $\begin{array}{c}\text { Time } \\
(\mathrm{ms} / \mathrm{cycle})\end{array}$ & $\begin{array}{c}\text { Current } \\
(\mathrm{kA})\end{array}$ & Clamping Force $(\mathrm{kN})$ \\
\hline $\mathrm{T} 2$ & $800 / 40$ & - & - \\
\hline $\mathrm{T} 3$ & - & - & 6 \\
\hline $\mathrm{T} 4$ & $240 / 12$ & $\mathrm{I}_{2}=19 \pm 3$ & 6 \\
\hline $\mathrm{T} 5$ & - & - & - \\
\hline $\mathrm{T} 6$ & $100 / 5$ & - & - \\
\hline $\mathrm{T} 7$ & $100 / 5$ & $\mathrm{I}_{4}=8 \pm 1$ & 6 \\
\hline
\end{tabular}

Tab. 5 Hard welding mode parameters

\begin{tabular}{|c|c|}
\hline Parameter & Set values \\
\hline T4 & $60 / 3(\mathrm{~ms} /$ cycle $)$ \\
\hline I2 & $41(\mathrm{kA})$ \\
\hline F & $10(\mathrm{kN})$ \\
\hline
\end{tabular}

The goal of the experiments was to compare the effect of selected welding mode on:

- the strength of the welded joint that has been assessed by the tensile test,

- character of fracture areas test after tensile,

- the hardness of the weld joint, which was evaluated by the Vickers method,
- macro and microstructure using light and electron microscopy with EDS analyser.

The tensile test was carried out according to STN EN 10002-1 on a tensile machine ZD 10/90 with the velocity motion of transverse beam $4.5 \mathrm{~mm}$. $\mathrm{min}^{-1}$. The character of fracture areas was evaluated according to STN EN ISO 14329 [13]. Structural macro and micro analysis were performed on cross-sections of welded joints prepared by conventional metallographic techniques. Zeiss Axiovert 40 MAT light microscope with Zeiss AxioCam ERc 5s camera and JEOL JSM IT300LV electron microscope with Oxford Instruments EDS analyzer were used for observations. 

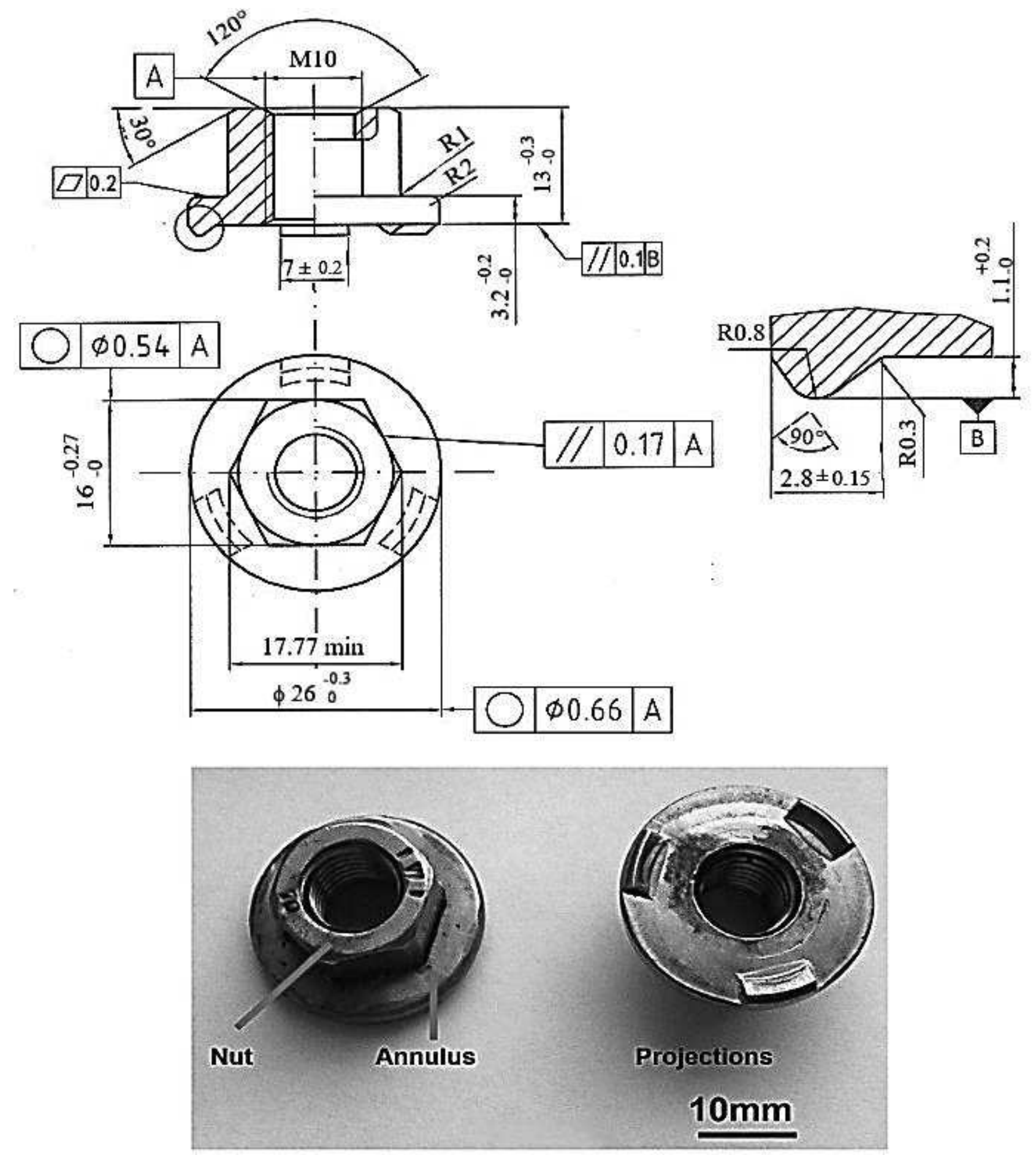

Fig. 1 Shape and dimensions of M10 nut for resistance projection welding

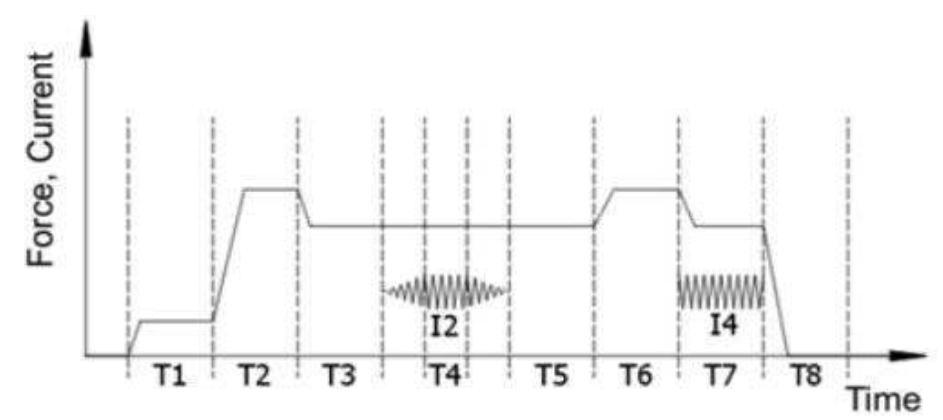

$\mathrm{T} 1$ - Electrodes close time

T2 - Press force increase time to calibration value T3 - Press force decrease time on welding value I2 - Welding current

T4 - Welding time

T5 - Current break in pulsed welding

T6 - Forging time

I4 - Annealing current

T7 - Annealing time

T8 - Pause time when welding multiple joints

Fig. 2 Course of the welding cycle 


\section{Evaluation of results achieved}

On Fig. 3 is a front view of a welded joint made by the soft welding mode (Tab. 4) from the nut side (Fig. 3a) and from the side of the galvanized sheet (Fig. 3b). From the Fig. 3a, it is evident that the heating of the welded materials was concentrated to the locations where three projections were located on the nut (see Fig. 1). There were no significant changes in the shape

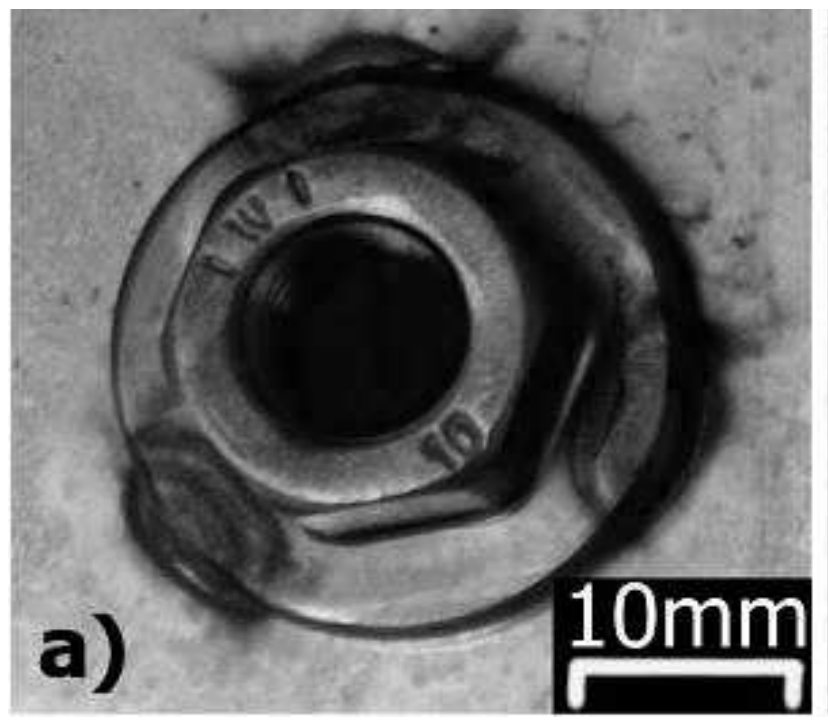

of the nut during heating. The view from the side of the galvanized sheet (Fig. 3b) shows that during the thermal cycle of the welding, the protective $\mathrm{Zn}$ layer was not damaged at the bottom of the steel sheet. Thus, the galvanized sheet retains the resistance to atmospheric corrosion at these locations. The same results in terms of the visual quality of welded joints were also obtained using the hard welding mode (Tab. $5)$.

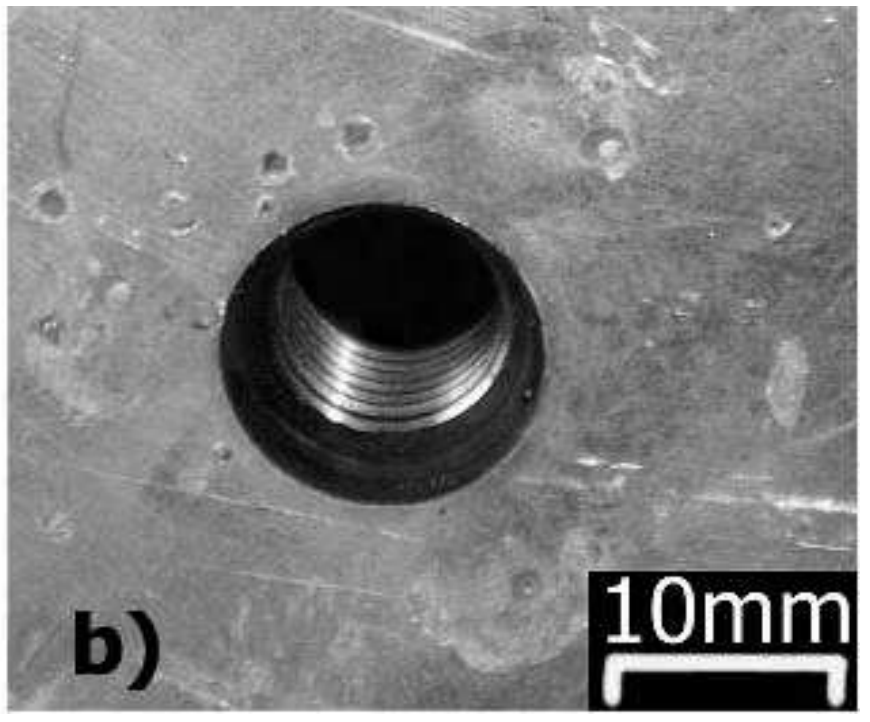

Fig. 3 Welded joint made by the soft welding mode (Tab. 4), a) Joint detail from the nut side, b) Joint detail from the galvanized sheet side

The tensile test results of samples made by the soft and hard welding mode are shown in Tab. 6 and Tab. 7. It is clear from the obtained data that the strength of joints produced by the hard welding mode (Tab. 5) was on average more than 2 times higher than the strength of joints in which the soft welding mode was used (Tab. 4). The lower strength was also reflected in the fracture characteristic of the samples welded by the lower current and the longer welding time (Fig. 4). The minimum joint strength limit has not been set. The requirement was to separate welded parts by occurring weld plug no interface fracture (according to standard EN ISO 14329).

Tab. 6 Measured $F_{\max }$ values from the tensile test of samples made by the soft welding mode

\begin{tabular}{|c|c|c|c|c|c|c|c|}
\hline Sample number & 37 & 38 & 39 & 40 & 41 & 42 & Average \\
\hline $\mathrm{F}_{\max }[\mathrm{N}]$ & 18110 & 16800 & 15650 & $\begin{array}{c}* * \text { Cross- } \\
\text { section }\end{array}$ & 16100 & 18100 & 16952 \\
\hline $\begin{array}{c}* \text { Fracture type } \\
\text { according of } \\
\text { STN EN ISO 14329 }\end{array}$ & $\mathrm{A}$ & $\mathrm{A}$ & $\mathrm{A}$ & - & $\mathrm{A}$ & $\mathrm{A}$ & - \\
\hline
\end{tabular}

Tab.7Measured $F_{\max }$ values from the tensile test of samples made by the hard welding mode

\begin{tabular}{|c|c|c|c|c|c|c|c|}
\hline Sample number & 45 & 47 & 48 & 49 & 50 & 52 & Average \\
\hline $\mathrm{F}_{\max }[\mathrm{N}]$ & 31400 & 36300 & $* *$ Cross section & 34300 & 37000 & 33900 & 34580 \\
\hline $\begin{array}{c}* \text { Fracture type } \\
\begin{array}{c}\text { according of } \\
\text { STN EN ISO 14329 }\end{array}\end{array}$ & $\mathrm{A} / \mathrm{B}$ & $\mathrm{B}$ & - & $\mathrm{B}$ & $\mathrm{B}$ & $\mathrm{A} / \mathrm{B}$ & - \\
\hline
\end{tabular}

*A - Disruption of the joint between the welded materials.

B - Disruption of the joint caused by tearing in the heat affected zone.

**Samples no. 40 (Tab. 6) and no. 48 (Tab. 7) were used for metallographic preparation of the cross section (Figs.

7 and 8), from which the structure of the welded joint produced by the soft and welding mode was analyzed. 
From the results of the evaluation of the fractures according to STN EN ISO 14329, it can be stated that the integrity of the joint made by using the soft welding mode (Tab. 6) was disrupted only between the welded materials (Fig. 4a). The average value of the cross-sectional area of the weld on samples made by the soft welding mode (samples no. 37 to 42 , tab. 6) is

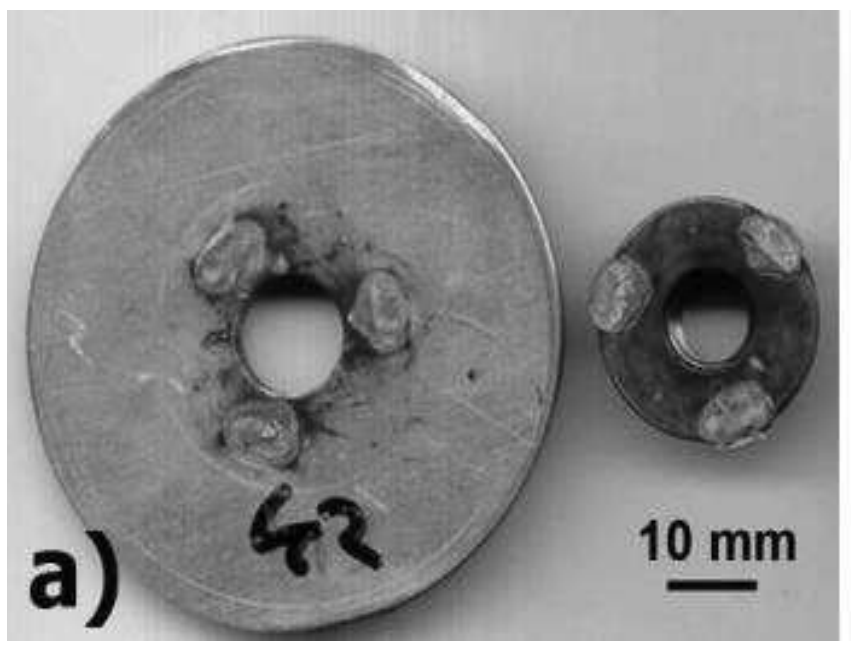

Fig. 4 Sample a) no. 42 made by the soft welding mode after tensile test, b) no. 50 made by the hard welding mode after tensile test

The overall view and details of the fracture areas on the sample produced by the soft welding mode are shown in Fig. 5.

According to the topography, the fracture at the selected nut area (Fig. 5a) can be characterized as mixed ductile/brittle mode fracture. Using scanning electron microscopy (SEM), it was found that fracture in the location „A“ (Fig. 5b) has the character of a cleavage fracture. The detail in Fig. 5c clearly documenting a river pattern of a transgranular brittle fracture in the middle of the joint. On the contrary, the surrounding area (location „B“, Fig. 5b) has the character of a ductile, intergranular dimple fracture (Fig. 5d).

A fracture area was analyzed on a hard welding mode sample where the joint was disrupted by tearing in the heat affected zone of the nut (Fig. 6a). The detail of the fracture area is shown in Fig. 6b. The SEM image (Fig. 6c) documents the shear fracture that occurred after plastic deformation of the material during the tensile test.

One sample was selected from each series (Tab. 6 and Tab. 7) to measure hardness and evaluate the macro and micro structure. The weld macrostructure of the sample made by the soft welding mode is shown in Fig. 7, and by the hard welding mode in Fig. 8. It can be seen from the figures that the various resistance welding parameters have been shown in the macrostructure of the joint. The soft welding mode (Tab. 6) caused the heating of the annular part of the nut (on
$109 \mathrm{~mm}^{2}$. Data were obtained from the interface fracture (Fig. 4a) by image analysis. On the other hand, when using the hard welding mode (Tab. 7), in most cases the joint was disrupted by tearing in the heat affected zone of the steel nut (Fig. 4b) - the mean value of the weld diameter (according to STN EN ISO 14329) was from $5.76 \mathrm{~mm}$ to $5.99 \mathrm{~mm}$.

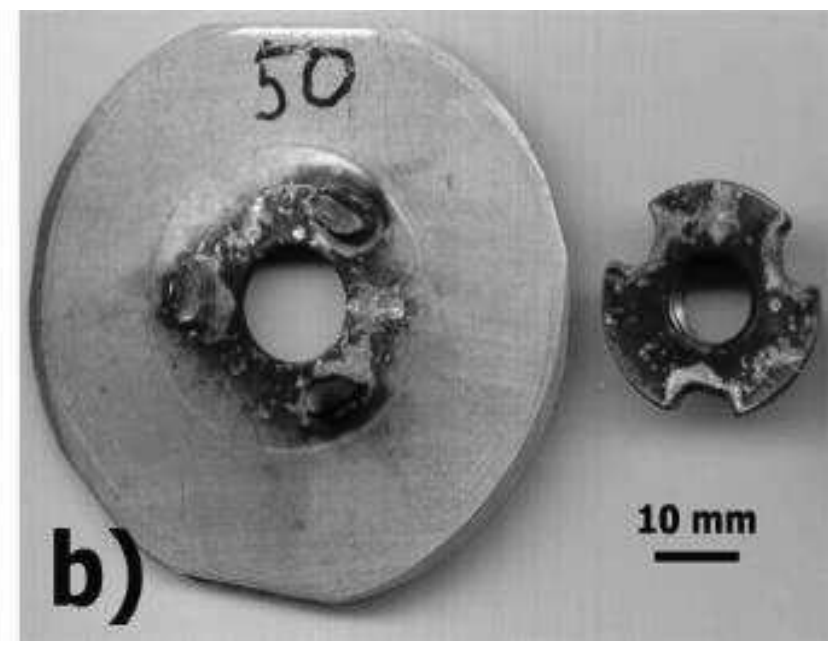

which the projections were made, see Fig. 1) almost over all its width (Fig. 7a). No cracks or shrinkage cavities were observed on the joint. However, lack of fusion occurred on the outside (Fig. 7b), and strips of the projections on the inside of the joint (Fig. 7c). The sheet was affected by the thermal cycle of welding to $1.9 \mathrm{~mm}$ depth from the original interface of the weld surfaces. No extruded metal were observed at the edges of the weld joint.

When using the hard welding mode (Tab. 7), the annular part of the nut with the projections was heated unevenly. The boundaries of the heat affected zone and the unaffected material indicate that the nut heating was preferably located at the point of the projection and at the top of the annular part where the electrode contacted the nut during welding (Fig. 8a). The heating was caused by the transition electrical resistance between the electrode and the nut surface. No intense heat dissipation caused greater overheating of the outer edge of the annular part of the nut, which caused the occurrence of extruded metal when the higher clamping force was interacted (Fig. 8b). The welded sheet was influenced by the thermal cycle of welding to a depth of $1.3 \mathrm{~mm}$ from the original interface of the weld surfaces. Also, on the sample produced by the hard welding mode, there were observed no cracks or shrinkage cavities in the cross section of the joint. No lack of fusion were identified from the outside of the joint, discontinuities are evident from the inside of the joint (Fig.8c). 

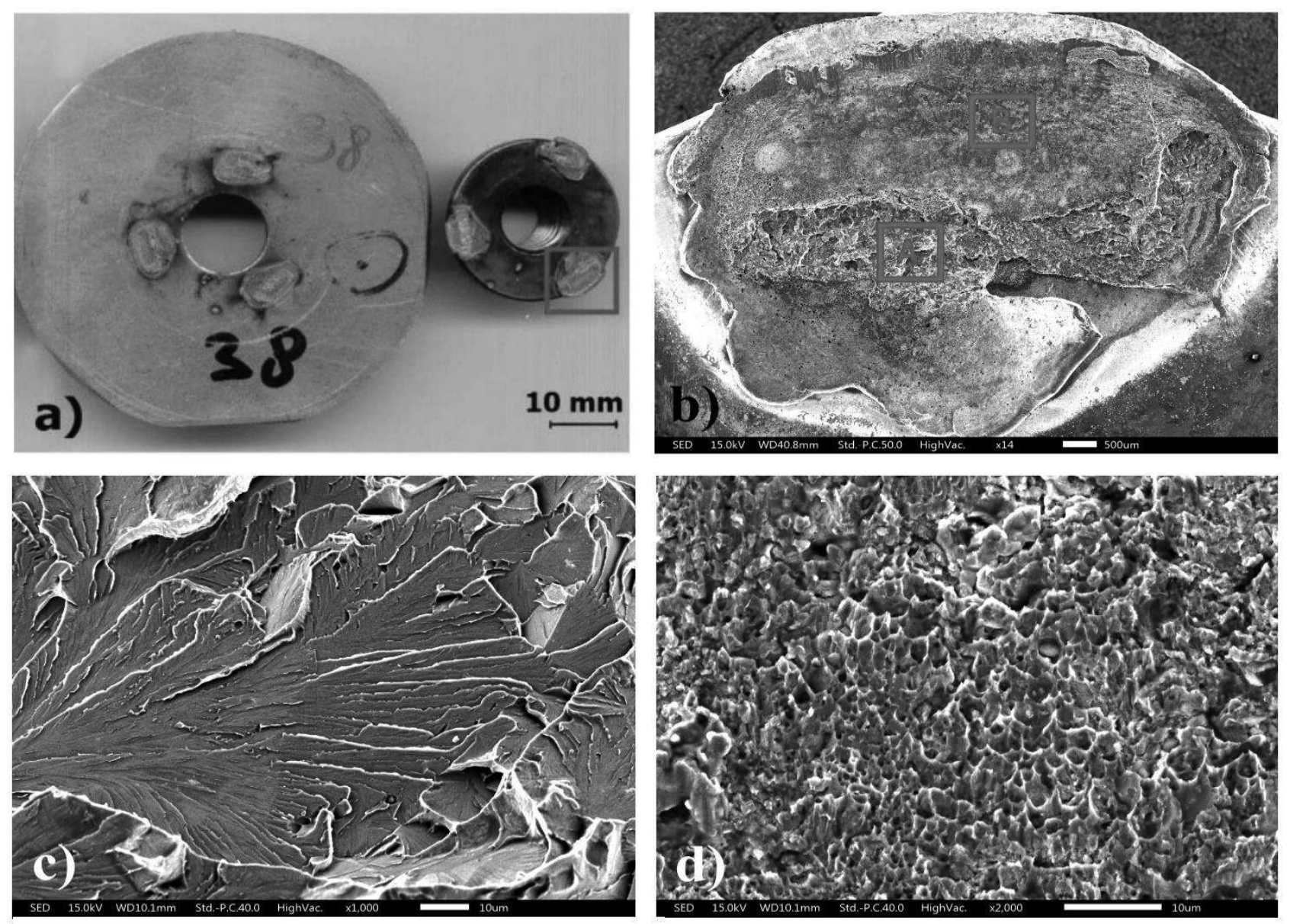

Fig. 5 The sample no.38 made by the soft welding mode a) overall view, b) detail of the fracture area, c)fracture area in the location " $A$ ", d) fracture area in the location " $B$ "
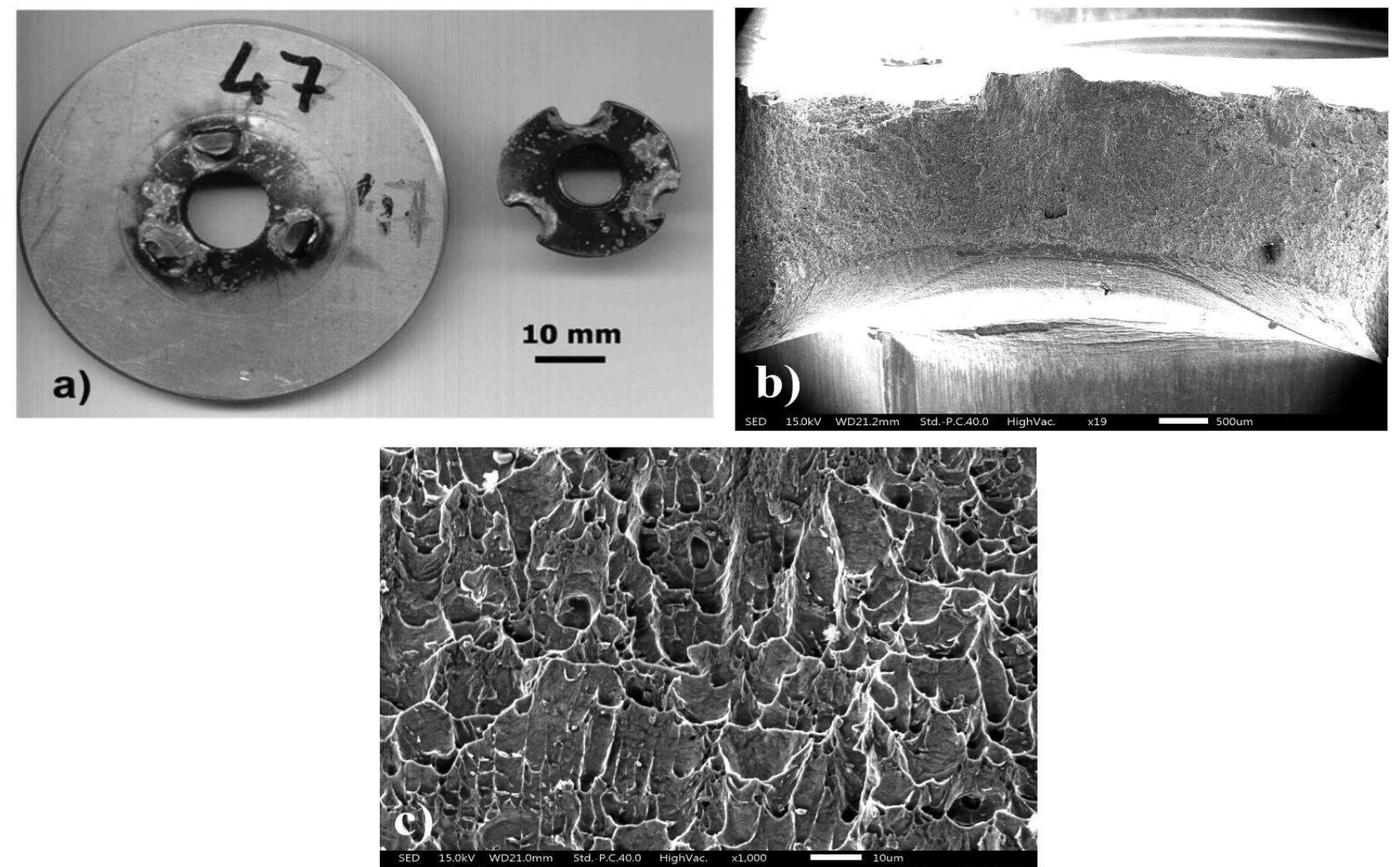

Fig. 6 The sample no. 47 made by the hard welding mode a) overall view, b) detail of the fracture area, c) microstructure of the fracture area 
One sample was selected from each series (Tab. 6 and Tab. 7) to measure hardness and evaluate the macro and micro structure. The weld macrostructure of the sample made by the soft welding mode is shown in Fig. 7, and by the hard welding mode in Fig. 8. It can be seen from the figures that the various resistance welding parameters have been shown in the macrostructure of the joint. The soft welding mode (Tab. 6) caused the heating of the annular part of the nut (on which the projections were made, see Fig. 1) almost over all its width (Fig. 7a). No cracks or shrinkage cavities were observed on the joint. However, lack of fusion occurred on the outside (Fig. 7b), and strips of the projections on the inside of the joint (Fig. 7c). The sheet was affected by the thermal cycle of welding to $1.9 \mathrm{~mm}$ depth from the original interface of the weld surfaces. No extruded metal were observed at the edges of the weld joint.

When using the hard welding mode (Tab. 7), the annular part of the nut with the projections was heated unevenly. The boundaries of the heat affected zone and the unaffected material indicate that the nut heating was preferably located at the point of the projection and at the top of the annular part where the electrode contacted the nut during welding (Fig. 8a). The heating was caused by the transition electrical resistance between the electrode and the nut surface. No intense heat dissipation caused greater overheating of the outer edge of the annular part of the nut, which caused the occurrence of extruded metal when the higher clamping force was interacted (Fig. 8b). The welded sheet was influenced by the thermal cycle of welding to a depth of $1.3 \mathrm{~mm}$ from the original interface of the weld surfaces. Also, on the sample produced by the hard welding mode, there were observed no cracks or shrinkage cavities in the cross section of the joint. No lack of fusion were identified from the outside of the joint, discontinuities are evident from the inside of the joint (Fig.8c).
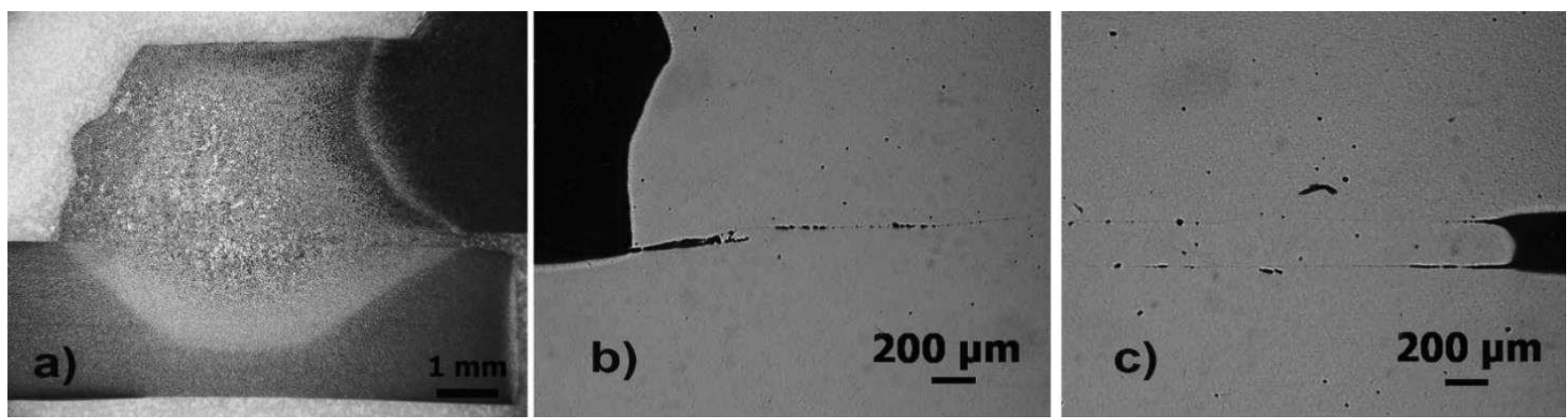

Fig. 7 Cross section of welded joint of sample no. 40 made by the soft welding mode a) overall view (etched in Nital), b) detail of outer side (polished), c) detail of inner side (polished)
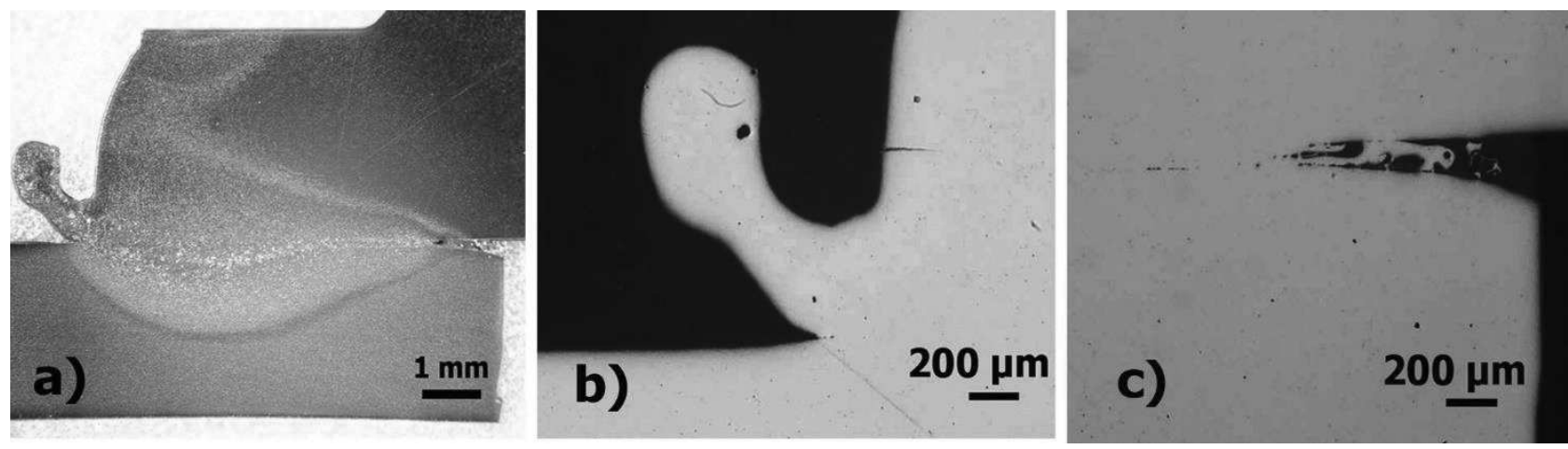

Fig. 8 Cross section of welded joint of sample no. 48 made by the hard welding mode a) overall view (etched in Nital), b) detail of outer side (polished), c) detail of inner side (polished, etched in Nital)

The interface details and the Zn distribution map between the nut and the welded sheet on the samples produced by the hard and soft welding mode are shown in Fig. 9 and Fig. 10. The details of the cross sections of the both samples show a sharp interface between the nut and the galvanized steel sheet. There was no fusion zone between the bonded materials in either case. Thus, the both welding modes used correspond to the solid-state welding principle. While using the soft welding mode the interface was more or less plane (Fig. 9), with hard welding mode (higher welding current and clamping force), the material surface of the galvanized sheet metal DP 600 was significantly deformed (Fig. 10). When using the soft welding mode, a strip was created after the deformation of the high-heated mate rial of the "V"-shaped projection (Fig. 1). The creep of the projections material during deformation was toward the center of the nut. In the 
hard welding mode, the reason of discontinuity on the inside of the nut was a spatter of small volume of molten projection material into the parting line between the joined materials. There was no deformation of the projection and no strip formation in this case. Figs. 9e, $9 \mathrm{f}$, and $9 \mathrm{~g}$ show that the structure of the joint on the sample made by the soft welding mode contains an increased amount of $\mathrm{Zn}$ under the strip at the interface of the weld surfaces.

Its occurrence is caused by insufficient overheating of the contact surface of the welded sheet DP 600 in this location, which is a direct consequence of rapid heat dissipation into the nut and electrodes. Increased Zn content (Figs. 9b, 9c, and 9d) was no already detected at the interface of the welded surfaces in the joint structure towards the outer edge of the nut. This is probably due to the evaporation of the $\mathrm{Zn}$ coating caused by the local heating of the surface of the bonded galvanized sheet above the temperature of $\mathrm{Zn}$ evaporation $907^{\circ} \mathrm{C}$. The wide occurrence of locations with high $\mathrm{Zn}$ content in the parting line between the welded materials as well as the occurrence of lack of fusion (Fig. 7b) thus negatively affected the resulting weld joint strength.

Figs. $10 \mathrm{~b}$ to $10 \mathrm{e}$ show that in the hard welding mode, the $\mathrm{Zn}$ layer of galvanized steel sheet was almost completely evaporated during heating. Concentration differences in the $\mathrm{Zn}$ content of the bonded materials and on the original interface were not observed around the joint. Small differences were found only close to the weld joint boundary from the inside of the nut (Figs. 10f and 10g). A sharp interface between the welded materials was visible on the crosssection of the joint made by the hard welding mode (Fig. 10a). During heating, the interface between the surface of the sheet metal and the projection of the nut did not disappear but remained (joint without dilution of welded metals). The cause could be rapid heat dissipation from the joint.

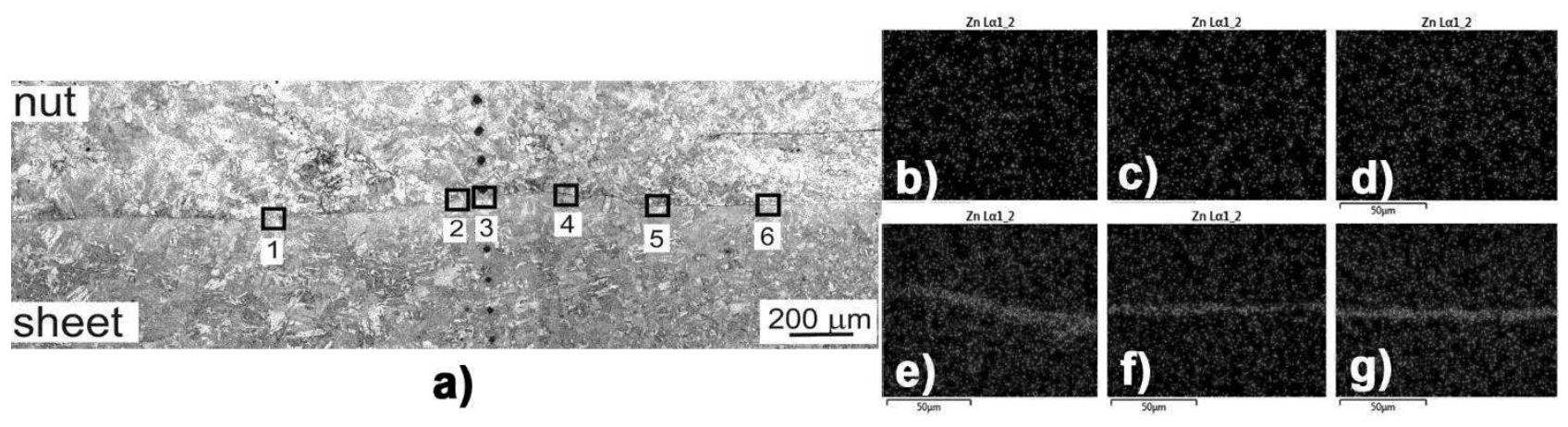

Fig. 9 Detail of the interface between welded materials on sample no. 40 (Tab. 6) made by the soft welding mode (a), and the Zn distribution in location "1" (b), "2" (c), "3" (d), "4" (e), "5" (f), "6" (g)

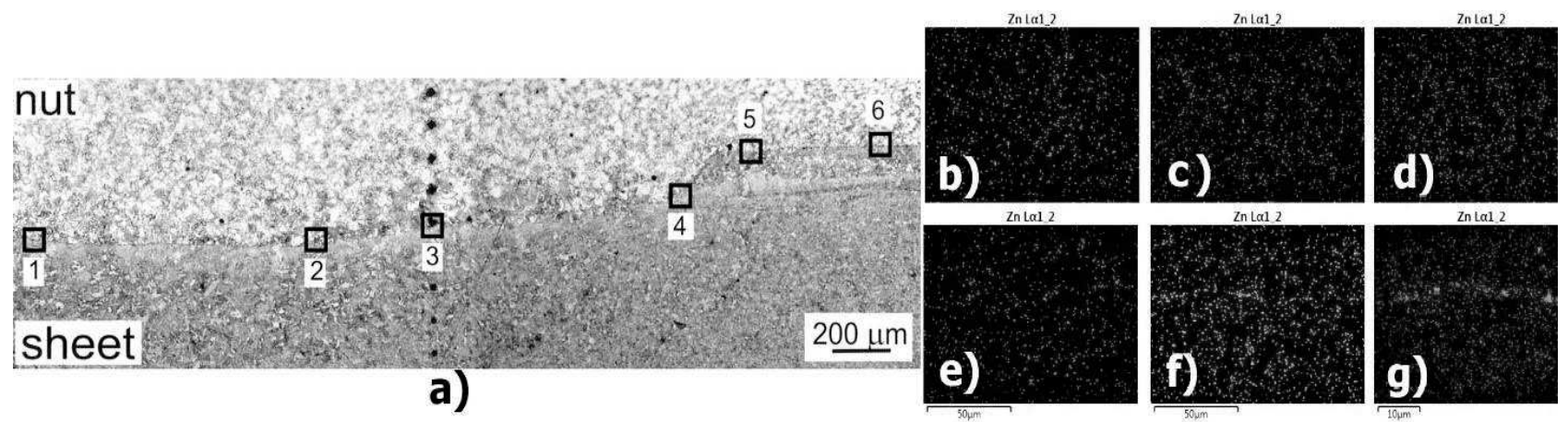

Fig. 10 Detail of the interface between welded materials on sample no. 48 (Tab. 7) made by the hard welding mode (a), and the Zn distribution in location "1" (b), "2" (c), "3" (d), "4" (e), "5" (f), "6" (g), "7" (b), "8" (i)

The HV0.1 microhardness course across the welded joint on the cross sections of selected samples is shown in Fig. 11. The values obtained in both cases confirm the character of the solid-phase pressure welding. A significant change in hardness at the interface of the welded materials was noted on the sample produced by the soft welding mode (sample no. 40, Fig. $11 \mathrm{a}$, as well as hard welding mode (sample no. 48, Fig. 11b).

\section{Microstructure of welded joint}

The base structure of welded steel DP 600 is documented in Fig. 12a. It consists of a ferritic matrix $\left(, \mathrm{F}^{\circ}\right)$ and islets of dispersed reinforcing phase, which in this case is martensite (,M“). The row-like arrangement of the reinforcing phase is the result of the production of the sheet by controlled rolling. The basic hardness of the material depends on the chemical 
composition and manufacturing method. The chemical composition of the material used (Tab. 2) and the

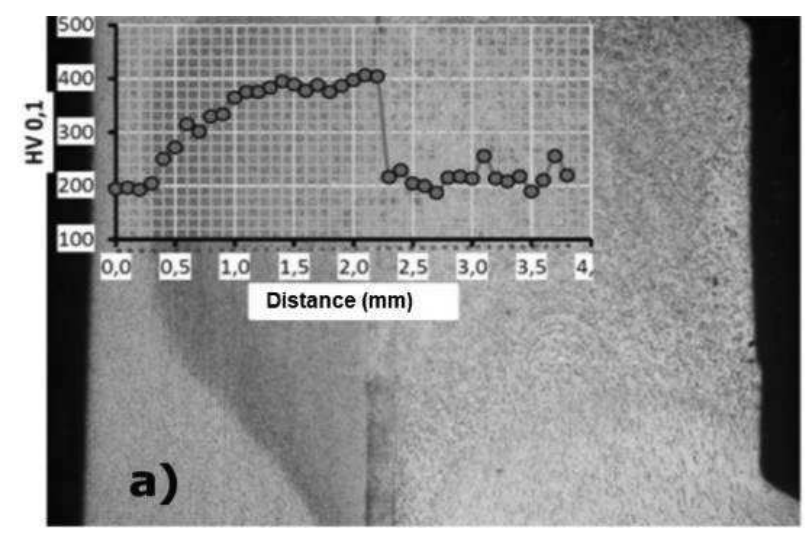

manufacturing method correspond to an average hardness of 194 HV0.1

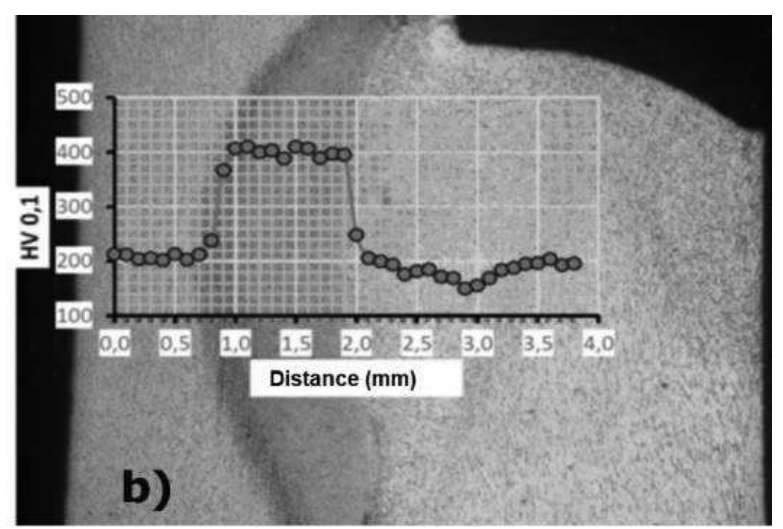

Fig. 11 Microhardness course HVO.1 a) of sample no. 40 made by the soft welding mode, b) of sample no. 48 made by the hard welding mode
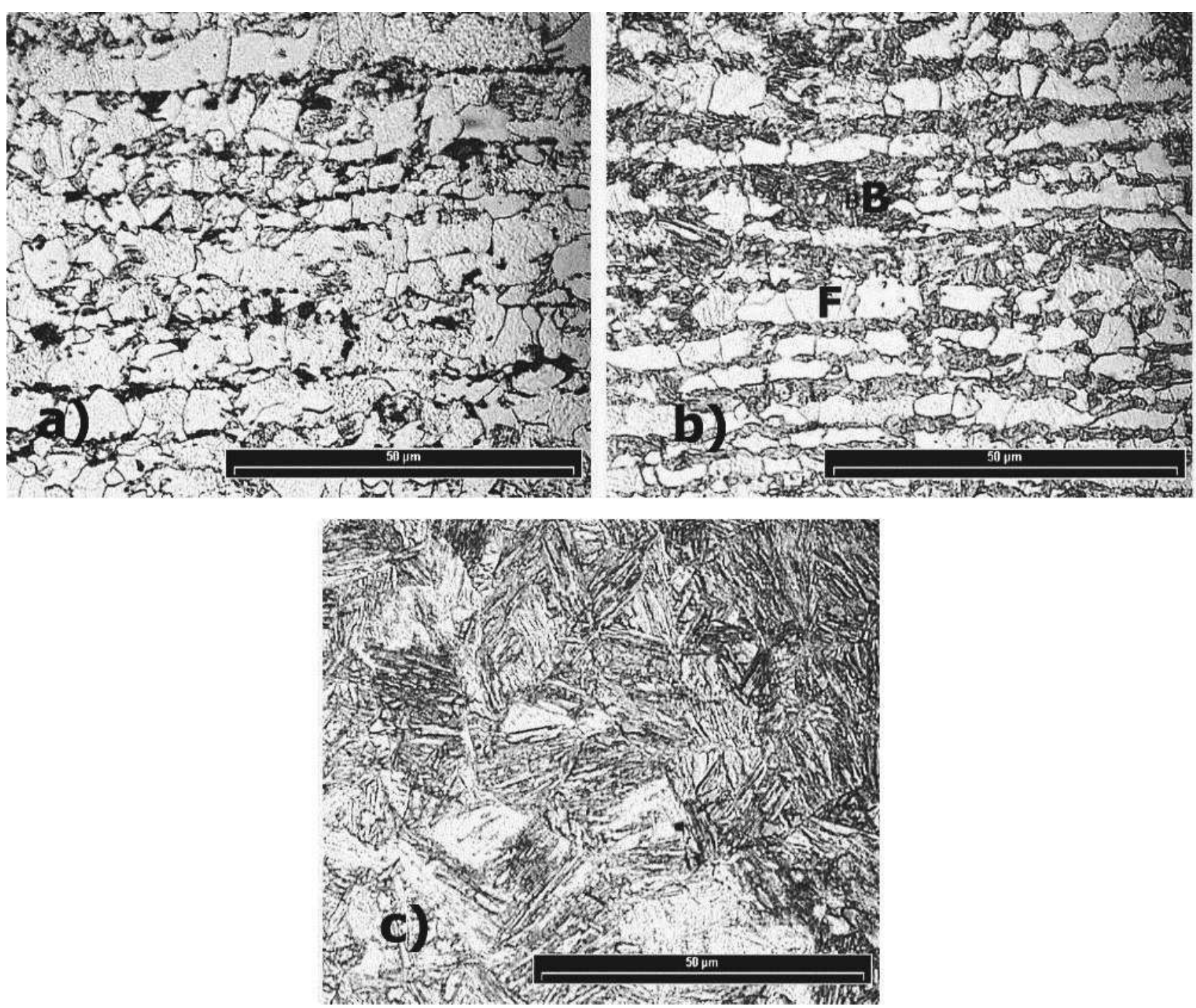

Fig. 12 Microstructure a) of DP 600 steel, b) of ICHAZ of sample no. 40, c) of CGHAZ of sample no. 40

In the heat affected zone of the weld joint made by the soft welding mode on the side of the galvanized sheet DP 600, we can observe a continuous increase in hardness from the unaffected basic material towards the sheet-nut interface (Fig. 11a). The increase in hardness to a maximum value of 406 HV0.1 corresponds to the structural changes in the heat affected zone of the galvanized steel sheet. The 
structure of the intercritical heat affected zone (ICHAZ) is shown in Fig. 12b. It consists of ferrite $\left(, \mathrm{F}^{\circ}\right)$, coarsed bainite $\left(, \mathrm{B}^{\circ}\right)$ or martensite. During heating, the martensite becomes coarse due to its dissolution after the temperature exceeds $A_{c 1}$. A further increase in the maximum temperature to $A_{c 3}$ cause a greater portion of the ferrite that has been transformed in ICHAZ into austenite. As a result of the subsequent rapid cooling, austenite disintegrates into martensite and lower bainite. These changes were demonstrated in this case by an increase of hardness in ICHAZ up to 300 HV0.1 (Fig. 11a). The structure of the coarse-grained heat affected zone (CGHAZ) shown in Fig. 12c consisted mainly of martensite („M" $\left.\mathrm{M}^{\circ}\right)$, which was also reflected in the maximum measured hardness of 406 HV0.1. The results obtained correspond to the results published for example in works $[14,15]$. Using the hard welding mode a narrower heat affected zone (1.3 $\mathrm{mm}$ wide) was formed from the side of the galvanized sheet DP 600 . The course of measured hardness values (Fig. 11b) shows a sharp increase in the narrow ICHAZ from 202 to 367 HV0.1. These changes are due to the higher
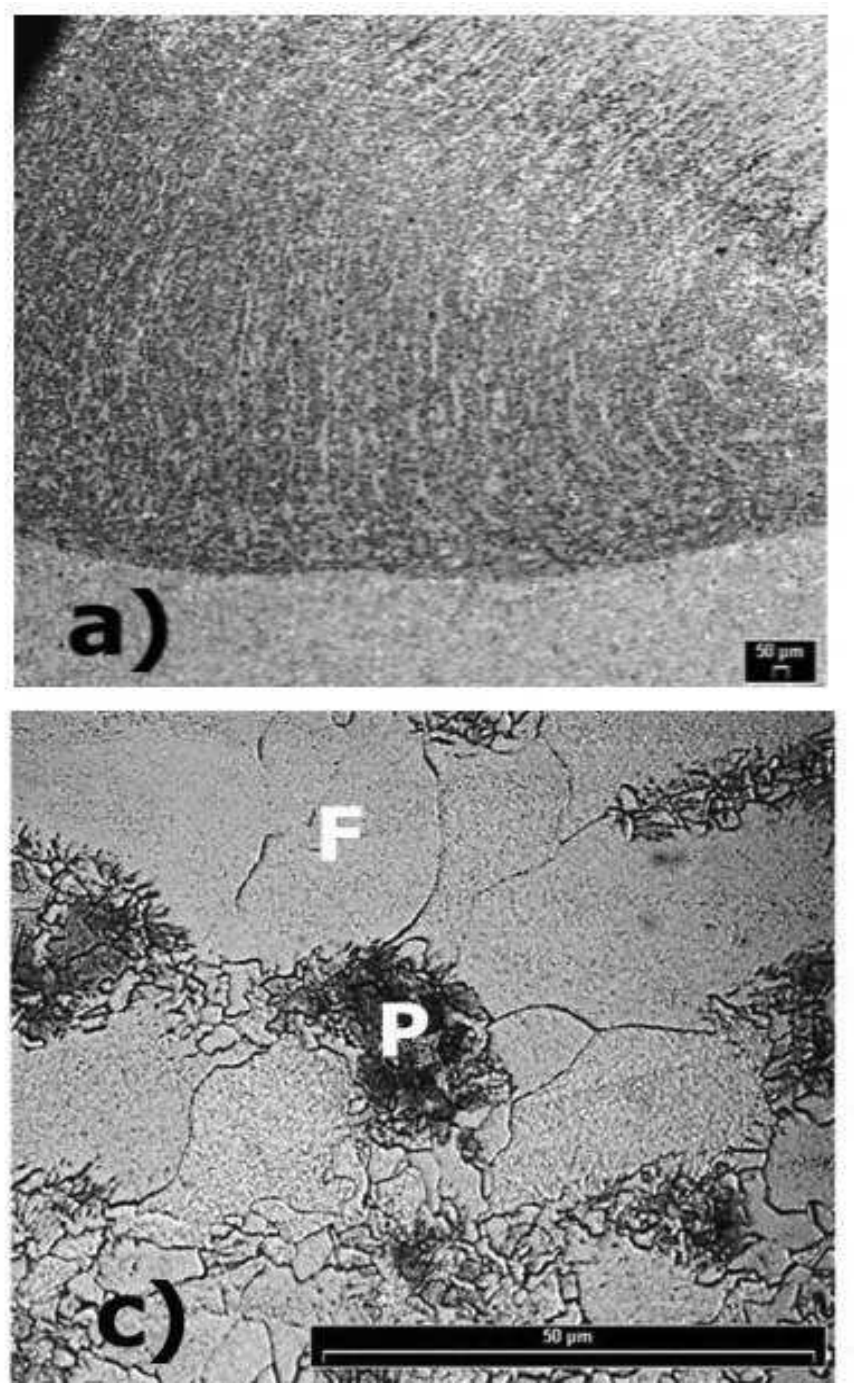

Fig. 13 Structure (sample no.48) a) of annular part of nut, b) of nut, c) of ICHAZ, c) of CGHAZ cooling rate when using the hard welding mode compared to the soft welding mode. Significant changes in the effect of hard and soft welding mode on structure and hardness in CGHAZ were not observed.

The deformation texture of the annular part of the nut M10, which is characteristic of forging technology, is visible in Fig. 13a. The ferritic-pearlitic („F+P structure (Fig. 13b) and hardness 204 HV0.1 (Fig. 11b) of the base material correspond to the chemical composition (Tab. 3) and the hardening during solid forming in the manufacturing. The decrease in hardness in the subcritical heat affected zone (SCHAZ) to 150 HV0.1 is due to the recrystallization of the original structure. Changes in the ICHAZ are documented in Fig. 13c. The structure consists predominantly of ferrite $\left(, \mathrm{F}^{\circ}\right)$ and recrystallized perlite $\left(, \mathrm{P}^{\star}\right)$. The increase in hardness due to these changes was only minimal. The CGHAZ from the nut side (Fig. 13d) is made of ferrite („F“), upper bainite („UB“), lower bainite $\left(, \mathrm{LB} \mathrm{C}^{\circ}\right)$, and martensite $\left(, \mathrm{M}^{\circ}\right)$ with a maximum hardness of 248 HV0.1. Again, the occurrence of nonequilibrium phases is subject to high cooling rates.
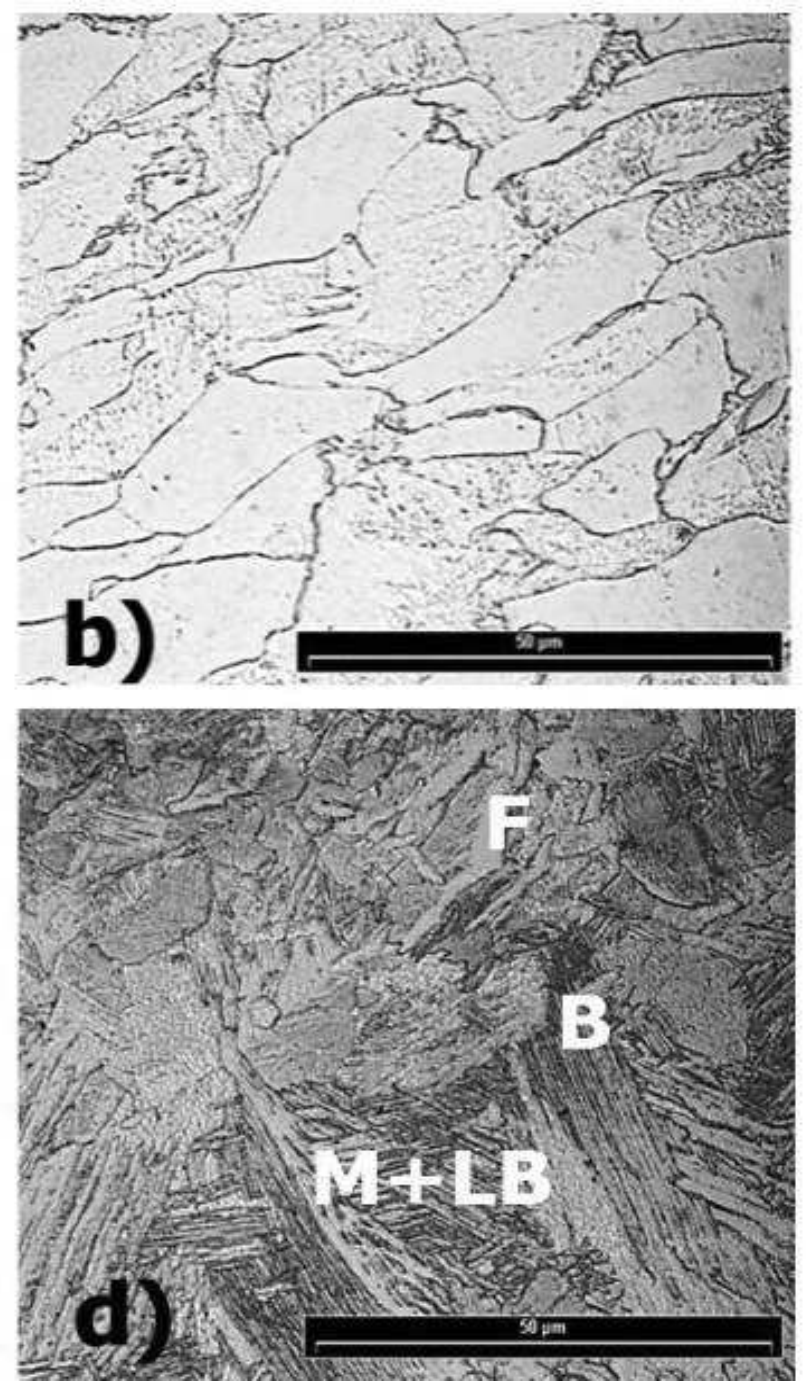


\section{Conclusion}

From the results of the resistance projection welding of M10 steel nuts to galvanized steel sheet DP 600 the following conclusions can be made:

- The hard welding mode (high welding current, welding force and short welding time) provided 2 times higher strength of the weld joints as the soft welding mode.

- When using the soft welding mode, the formation of strips on the inside of the joint was observed. They were formed during heating and deformation of the projection. In the hard welding mode, discontinuities due to metal spatter from the projection during rapid heating were observed. The occurrence of extruded metal has been observed from the outside of the joint. In the soft welding mode lack of fusion were observed on this side, which had a negative impact on the weld strength.

- Even if in no case were the conditions for the formation of fusion welded joints achieved, in the case of the hard welding mode, during the tensile test in most cases the joint was disrupted by tearing in the heat affected zone (evaluated according to STN EN ISO 14 329). When using the soft welding mode, the fracture surface had a mixed character-it formed locations of a brittle cleavage fracture and ductile shear fracture.

When using the soft welding mode an increased $\mathrm{Zn}$ concentration from the sheet metal coating was measured in the transition area between the welded materials at the strip locations. The cause of such locations was insufficient heating of the galvanized sheet metal surface below the $\mathrm{Zn}$ evaporation temperature. When applying the hard welding mode, only a slight increase in the $\mathrm{Zn}$ concentration was observed at the inner boundary of the weld joint.

- The use of the hard welding mode was also manifested in the narrower heat affected zone from the side of the welded sheet DP 600. The course of hardness and structure of individual heat affected zones corresponds to the already published results of the evaluation of resistance weld joints of two-phase steels.

\section{Acknowledgement}

The results given in this paper were obtained as part of VEGA 1/0405/19 research project. Support of the UVP STU Bratislava ITMS 26240220084 project is also acknowledged.

\section{References}

[1] LARSSON, J. (2008). Projection welding for nut and bolt attachment. The Fabricator. https://www.thefabricator.com/article/shopmanagement/projection-welding-for-nut-andboltattachment. Accessed 14 Apr 2018

[2] CHAMBERS, A.H. (2001). Principles and Practices of Stud Welding.In: PCI Journal, Vol. 46, No 5, pp. 46-58.

[3] LARSSON, J.K., BENGTSSON, L. (2007). The overlooked joining technology of fasteners for modern car body structures - Latest experience from nut and bolt attachment to advanced high strength steels. In: 11th European Automotive Engineers' Council (EAEC), Hungary.

[4] SEJČ, P., BELANOVÁ, J. (2019). The Effect of Welding Parameters on the Properties of Join between Studs and Steel Sheet USIBOR Type 22MnB5. In: Manufacturing Technology, 19(3), pp. 492-498. ISSN 1213-2489

[5] KRAMÁR, T., KOLAŘíK, L., KOLAŘíKOVÁ, M., SAHUL, M., POSPÍŠIL, D. (2014). Capacitor Discharge Welding of Aluminium Studs. In: Manufacturing Tecbnology, 14(2), pp. 199-206. ISSN 1213-2489

[6] ZHANG H., SENKARA J. (2017). Resistance Welding: Fundamentals and Applications, 2nd Edition. pp. 456. CRC Press.

[7] WANG, X., ZHANG, Y. (2017). Effects of Welding Procedures on Resistance Projection Welding of Nuts to Sheets. In: ISIJ International, Vol. 57, No. 12, pp. 2194-2200. ISSN 13475460.

[8] RINGSBERG, J.W., ORVEGREN, P., HENRYSSON, H.F., ÅKERSTRÖM, G. (2008). Sheet metal fatigue near nuts welded to thin sheet structures. In: International Journal of Fatigue, No.30, pp.877-887. ISSN 0142-1123

[9] NIELSENA, C.V., ZHANGB, W.P., MARTINSC, A., BAY F.N. (2015). 3D numerical simulation of projection welding of square nuts to sheets. In: Journal of Materials Processing Technology, 215, pp.171-180. ISSN 0924-0136.

[10] ZHU, W. F., LIN, Z. Q., LAI, X. M., and LUO, A. H. (2006). Numerical analysis of projection welding on auto-body sheet metal using a coupled finite element method. In: $J$ Adv Manuf Technol, 28, pp.45-52. ISSN 2289-8107.

[11] MIKNO, Z. (2018). Projection welding of nuts involving the use of electromechanical and pneumatic electrode force. In: The International Journal of Advanced Manufacturing Technology, No.99, pp.1405-1425. ISSN 1433-3015. 
[12] STN EN ISO 14329 Odporové zváranie - Deštruktívne skúšky zvarov - Typy porušení a geometrické meranie odporových bodových, švových a výstupkových zvarov.

[13] CHENYU-WANGMIN, W. (2005). Effects of surface treatments of galvanized steels on process properties of projection welding. In: Welding in the World, Vol. 49, No. 1/2, pp.39-41. ISSN 0043-2288.
[14] NAYAK, S.S., ZHOU, Y. (2012). Resistance Spot Welding of Dual-phase Steels: Heat affected zone softening and tensile properties. In: Trends in Welding Research, Proceedings of the 9th International Conference June 4-8, Chicago, Illinois, USA

[15] KHAN, M. I., KUNTZ, M. L., BIRO ZHOU, E.Y. (2008) Microstructure and Mechanical Properties of Resistance Spot Welded Advanced High Strength Steels. In: Materials Transactions, Vol. 49, No. 7 pp. 1629 -1637. 